\title{
ASSESSMENT OF URBAN HEAT ISLAND IN BILASPUR CITY, CHHATTISGARH
}

\author{
Z. T. Khan ${ }^{1}$ and Dipankar Bera ${ }^{2}$ \\ ${ }^{1}$ Ex-Professor \& Dean of Science Faculty, ${ }^{2}$ Research Scholar, \\ SOS in Geography, Pt. Ravi Shankar Shukla University, (CG), India \\ Email: beradipankar79@yahoo.com
}

\begin{abstract}
The air temperature is gradually rising in all cities of the world. One of the possible causes is the drastic reduction in the vegetation cover in cities. In 1971 Indian Census the city's population had 98,410 but now it has 3, 35,293 (2011 Indian Census) population. In the cities over the last fifty years has become over populated. Bilaspur city of Chhattisgarh is experiencing rapid industrialization which has resulted remarkable UHI. The LULC map of the study area developed for the year 2002 and 2017 using supervised classification method. Eight land use classes have been identified as Built-upland, mixed Built-up, Water bodies, Agricultural fields, Tree clad area, Open land, Industry and River Sand. Using bands 1- 4 of Landsat 7 and 2 - 5 of Landsat 8 the pre-processed images the land use land cover pattern was mapped by Visual interpretation of Arc GIS 10.3 software. Urban heat island phenomenon is evident from the LST images. Understanding the distribution of Land Surface Temperature (LST) and its spatial variation will be helpful to urban developer and also to find out present urban crisis and possible solution. Investigate and identify land used types which have the most active role to the increase of ambient temperature in Bilaspur City. Landsat 7 ETM+ images of 2002 and Landsat 8 TIRS image of 2017 obtained from USGS and used for the study. Using bands 1- 4 and 7 of Landsat 7 ETM+ and 2-5 and 10, 11 of Landsat 8 TIRS for processing the LST and NDVI map. The digital number of thermal infrared band is converted into spectral radiance using the equation supplied by the Landsat user's hand book. The effective at-sensor brightness temperature is obtained from the spectral radiance using Plank's inverse function. The study reveals that appropriate urban planning is necessary for the sustainable development of the urban area.
\end{abstract}

Key words: Urban Heat, Surface Temperature, Normalized Difference Vegetation Index.

\section{Introduction}

Rapid urbanization has significant role on different aspects of the quality of life and research in determining the patterns of urbanization and quantifying their impacts is the need of the time. The changes in land use and land cover include loss of agricultural lands, loss of forest lands, increase of barren area, increase of impermeable surface of the area because of the built up area, etc. Development of land use land cover is very much useful to the city planner and policy makers. For the sustainable urban ecosystems the amount of land required for growing the vegetation can be estimated from these studies. One of the major implications of urbanization is increase of surface temperature and development of Urban Heat Island. Surface temperature is increased by anthropogenic heat discharges due to energy consumption, increased land surface coverage by artificial materials having high heat capacities and conductivities, and the associated decrease in vegetation and water pervious surfaces which reduce the surface temperature through evapotranspiration. Landsat ETM+ images have widely used to observe the biophysical characteristics of the land surface. In addition to the development of Land use/cover maps band 6 of the Landsat imagery is useful for deriving the surface temperature. Urban Heat Island is one of the upcoming urban microclimatological problems developing in the city. Land surface temperature is gradually increasing in the urban area due to reduced vegetative cover and increased built-up surfaces with concrete, asphalt, object and material. Because of these phenomena certain parts of the urban area of the city are becoming extremely hot during day time and particularly during summer seasons, causing lot of discomfort to the citizens. 


\section{Literature Review}

There are so many studies done by Geographers, Planners, and Scientists \& Researchers in the concerned filed. Oke, 1973, and Torok et al., 2001 described that even towns with populations of 1000 people had urban heating of about $2.2^{\circ} \mathrm{C}$ compared to the nearby rural countryside. The land-use and land-cover maps, four vegetation-impervious surface-soil (V-I-S) patterns of the city development were identified pertain to Mississauga's features. Another study report provided by Seto et al., 2002 described that the land-use changes into the Pearl River Delta, using Landsat TM. Field assessments confirm a high overall accuracy of the landuse change map (93.5\%) and support the use of change vectors and multi date Landsat TM imagery to monitor land-use change. Field-based accuracy assessment to identify problems in a land-use map and to improve area estimates for each class (Seto et al., 2002). Land surface temperature is sensitive to vegetation and soil moisture, hence it can be used to detect land use/land cover change, and e.g. tendencies towards urbanization, and deforestation etc. various studies have been carried out to investigate LST using the vegetation abundance (Weng et al., 2004). According to Mallik et al., 2008 estimated land surface temperature over Delhi using Landsat-7 ETM+. Argued that Satellite derived emissivity values were in the acceptable range and the NDVI and fractional vegetation cover are effective in deriving surface emissivity and surface.

\section{Study Area}

Bilaspur city has a District Headquarters of Bilaspur District in Chhattisgarh, situated $133 \mathrm{~km}$ (83 miles) north of the state capital, Naya Raipur. Bilaspur City Municipal population is 3, 35, 293, (2011census), which is the Third-largest city after Raipur and Bhilai-Durg. Bilaspur city is located on bank of Arpa River with latitude $22^{\circ} 6^{\prime} 5^{\prime \prime} \mathrm{N}$ to $22^{\circ} 6^{\prime} 30^{\prime \prime} \mathrm{N}$ and longitude $82^{\circ} 6^{\prime} 45^{\prime \prime} \mathrm{E}$ to $82^{\circ} 12^{\prime} 5^{\prime \prime} \mathrm{E}$. The climate is tropical, with hot summers and moderate winters. The peak temperature reaches $45^{\circ} \mathrm{C}$ in May- June, while the winter temperature is $23-27^{\circ} \mathrm{C}$ in month Dec-Jan. The average humidity is $78 \%$ and the average annual rainfall is $103 \mathrm{~cm}$. Bilaspur gets its rainfall from both the south-west monsoon and north-east monsoon. The topography of Bilaspur is flat, with a few small to medium sized hills. It is also a major railway junction connecting all states in the country. The Bilaspur city is the commercial capital of the state of Chhattisgarh. The geographical location study area of Bilaspur is shown in Fig. 1.

\section{Figure 01: Location of Study Area}

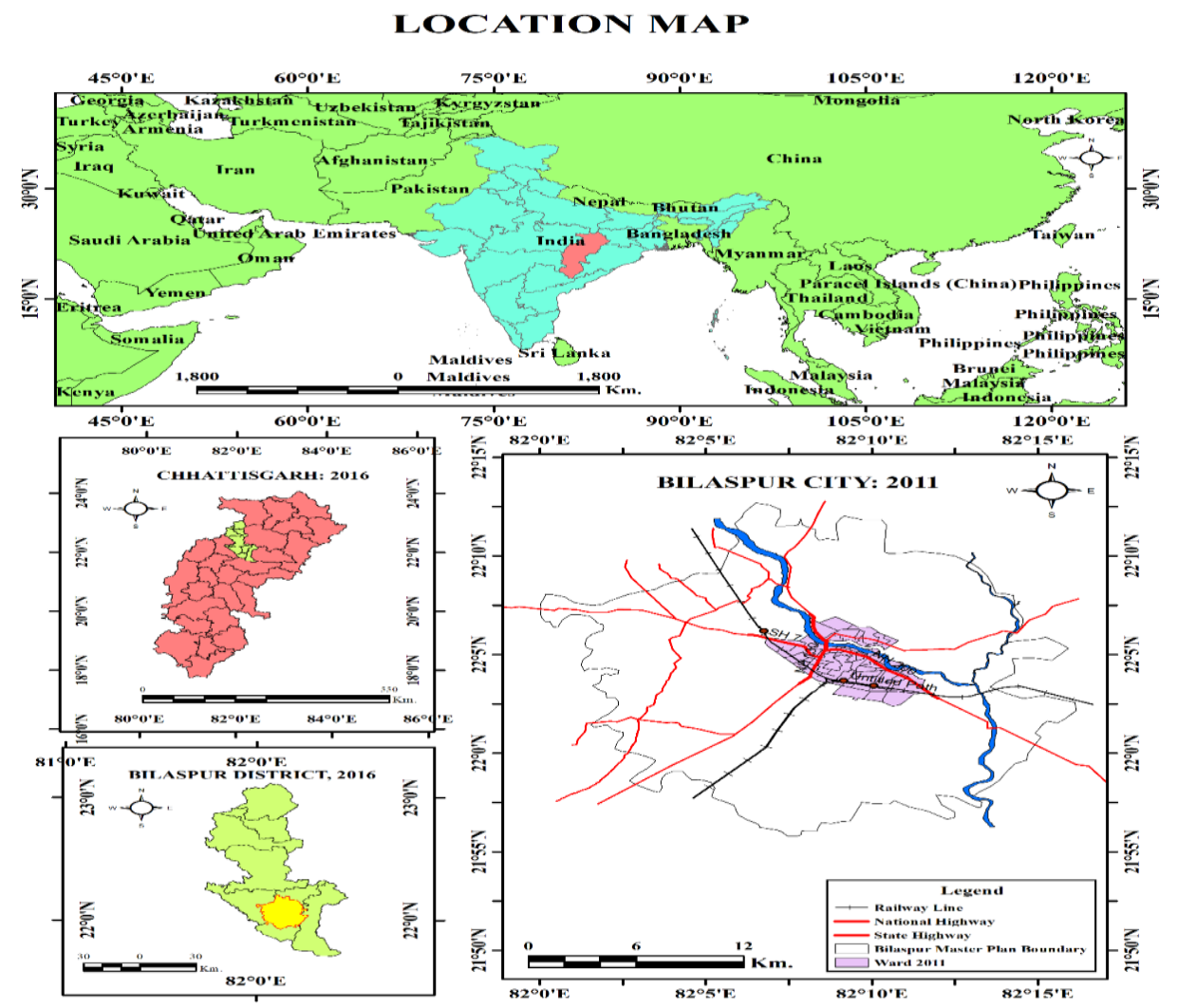




\section{Objectives}

The main objectives of the research paper are as follows:

- To study attempts to find changes in land use patterns of Bilaspur city in 2002 to 2017 and analyze the relation between the land use/cover and land surface temperature.

- $\quad$ To suggest planning strategies for future healthy urban development.

\section{Methodology}

For the present study the following methodology is adopted which involves satellite data download, classification of the imagery, development of land use/cover maps, preparation of NDVI maps, retrieval of Land Surface Temperature maps and correlation studies. Remote sensing has the capability of monitoring such changes, extracting the changes information from satellite data. In this work Landsat $7 \mathrm{ETM}+$ and Landsat 8 TIRS images of Bilaspur city has downloaded from USGS earth explorer web site. These are briefly outlined here.

\section{Data Download}

Cloud Free Landsat satellite data of 2002 and 2017 for the study area has been downloaded from USGS Earth Explorer website. All the data are pre-processed and projected to the Universal Transverse Mercator (UTM) projection system. The Landsat satellite image of the study area down loaded for the year 2002 and 2017. The study area is obtained by sub setting the image with a rectangular area of interest (AOI).

\section{Development of Land Use/Cover Map}

Using bands 1 - 4 of Landsat 7 and $2-5$ of Landsat 8 the pre-processed images the land use land cover pattern was mapped by Visual interpretation of Arc GIS 10.3 software. The eight classes considered for the study area are Built-upland, mixed Built-up, Water bodies, Agricultural fields, Tree clad area, Open land, Industry and River Sand.

\section{Derivation of NDVI Image}

The Normalized Difference Vegetation Index (NDVI) is a measure of the amount and vigor of vegetation at the surface. The reason NDVI is related to vegetation is that healthy vegetation reflects very well in the near infrared part of the spectrum. Green leaves have a reflectance of $20 \%$ or less in the 0.5 to 0.7 range (green to red) and about $60 \%$ in the 0.7 to $1.3 \mu \mathrm{m}$ ranges (near infrared). The value is then normalized to $-1<=N D V K_{<=1}$ to partially account for differences in illumination and surface slope. The index is defined by equation 1.

$\mathrm{NDVI}=(\mathrm{NIR}-\mathrm{RED}) /(\mathrm{NIR}+\mathrm{RED})$.

\section{RETRIEVAL OF LST}

\section{FROM LANDSAT 7 ETM+:}

The digital number (DN) of thermal infrared band is converted in to spectral radiance $\left(L_{\lambda}\right)$ using the equation supplied by the Landsat user's hand book.

$$
L_{\lambda}=\left\{\frac{\text { LMAX-LMIN }}{\text { QCALMAX-QCALMIN }}\right\}^{*} D N-1+L_{\text {MIN }}
$$

$\mathrm{L}_{\text {MAX }}=$ the spectral radiance that is scaled to QCALMAX in $W /\left(\mathrm{m}^{2}{ }^{*} \mathrm{sr}^{*} \mu \mathrm{m}\right)$

$L_{M I N}=$ the spectral radiance that is scaled to QCALMIN in $W /\left(m^{2 *} s^{*} \mu m\right)$

QCALMAX = the maximum quantized calibrated pixel value (corresponding to $L_{\text {MAX }}$ ) in

$\mathrm{DN}=255 \mathrm{QCALMIN}=$ the minimum quantized calibrated pixel value (corresponding

to $L_{\text {MIN }}$ ) in $D N=1$.

$L_{\text {MAX }}$ and $L_{\text {MIN }}$ are obtained from the Meta data file available with the image and are given in the Table 1 below.

Table 01: $L_{\text {MAX }}$ and $L_{\text {MIN }}$ values of Landsat data

\begin{tabular}{|c|c|c|c|}
\hline Band No & Satellite/ Sensor & LMAX & LMIN \\
\hline 6.1 & Landsat7 /ETM+ High gain & 12.65 & 3.2 \\
\hline 6.2 & Landsat7 /ETM + Low gain & 17.04 & 0.0 \\
\hline
\end{tabular}

The effective at-sensor brightness temperature $\left(T_{B}\right)$ also known as black body temperature is obtained from the spectral radiance .Conversion of spectral radiance to temperature in Kelvin.

$$
\mathrm{Tb}=\mathrm{K} 2 / \ln ((\mathrm{K} 1 / \mathrm{L})+1
$$

Where, $\mathrm{K} 1=$ Calibration constant 1

$\mathrm{K} 2=$ Calibration constant 2 
$\mathrm{Tb}=$ surface temperature

The calibration constants K1 and K2 obtained from Landsat data user's manual are given in the table 2.

Table 02: Calibration Constants for Thermal Band

\begin{tabular}{|c|c|c|}
\hline Sensor & K1 & K2 \\
\hline Landsat 7/ ETM+ & 666.09 & 1282.71 \\
\hline
\end{tabular}

\section{From Landsat 8 TIRS}

OLI and TIRS band data can be converted to TOA spectral radiance using the radiance rescaling factors provided in the metadata file:

$$
L_{\lambda}=M_{L} Q_{\text {cal }}+A_{L}
$$

Where:

$L_{\lambda}=$ TOA spectral radiance (Watts/ $\left(\mathrm{m} 2{ }^{*}\right.$ srad $\left.\left.^{*} \mu \mathrm{m}\right)\right)$

$M_{L}=$ Band-specific multiplicative rescaling factor from the

Meta Data (Radiance_mult_band_x, Where $\mathrm{x}$ is the band number)

$A_{L}=$ Band-specific additive Rescaling factor from the metadata

(Radiance_add_band_x, where $\mathrm{x}$ is the band number)

$Q_{\text {Cal }}=$ Quantized and calibrated standard product pixel values (DN)

Table 03: Rescaling Factor

\begin{tabular}{|l|c|c|}
\hline Rescaling Factor & Band 10 & Band 11 \\
\hline ML & 0.000342 & 0.000342 \\
\hline AL & 0.1 & 0.1 \\
\hline
\end{tabular}

IRS band data can be converted from spectral radiance to brightness temperature using the thermal constants provided in the metadata file:

$$
T=\frac{K 2}{\ln \left(\frac{K 1}{L_{\lambda}}+1\right)}
$$

Where:

$\mathrm{T}=$ At-satellite brightness temperature $(\mathrm{K})$

$\mathrm{L}_{\lambda}=$ TOA spectral radiance (Watts/ $\left(\mathrm{m} 2{ }^{*}\right.$ srad $\left.\left.^{*} \mu \mathrm{m}\right)\right)$

$\mathrm{K}_{1}=$ Band-specific thermal conversion constant from the metadata (K1_constant_band_x, where $\mathrm{x}$ is the thermal band number)

$\mathrm{K}_{2}=$ Band-specific thermal conversion constant from the metadata (K2_constant_band_x, where $\mathrm{x}$ is the thermal band number)

Table 04: K1 and K2 Values

\begin{tabular}{|l|c|c|}
\hline Thermal Constant & Band 10 & Band11 \\
\hline K1 & 1321.08 & 1201.14 \\
\hline K2 & 777.89 & 480.89 \\
\hline
\end{tabular}

22.3 Land Surface Emissivity to find LST it is necessary to calculate the LSE of the region. LSE was estimated using NDVI threshold method.

Where,

$$
L S E=\varepsilon S(1-F V C)+\varepsilon V * F V C
$$

$\varepsilon s$ and $\varepsilon v$ - soil and vegetative emissivity values of the corresponding bands.

Table 05: Emissivity Values

\begin{tabular}{|l|l|c|}
\hline Emissivity & Band 10 & Band 11 \\
\hline$\varepsilon S$ & 0.971 & 0.977 \\
\hline$\varepsilon \vee$ & 0.987 & 0.989 \\
\hline
\end{tabular}




\section{RESULTS AND DISCUSSION \\ Land Use/Cover Change Analysis}

The land use land cover map of the study area developed for the year 2002 and 2017 using supervised classification method. Eight land use classes have been identified as Built-upland, mixed Built-up, Water bodies, Agricultural fields, Tree clad area, Open land, Industry and River Sand. The LULC map is given in below as Fig.2 a \& 2 b. Post classification change analysis of land use and land covers have been calculated from the land use change detection using following formula (1-6)

Gain/increase $=\mathrm{Lt}+1-\mathrm{CP} \ldots \ldots \ldots 1$

Losses/decrease $=\mathrm{Lt}-1-\mathrm{CP} \ldots . .2$

Net Change $=$ Gain - Losses ........ 3

Gross change $=$ Gain + losses......4

Percent gains $=$ gain $* 100 / C P$ where,$C P>0$ else gain $* 100 \ldots \ldots .5$

Percent Losses $=$ Losses ${ }^{*} 100 / C P$ where, CP $>0$ else Losses *100......6

$\mathrm{L}=$ land use $/$ Land cover $\mathrm{t}=$ present time. $\mathrm{t}+1=$ Future time. $\mathrm{T}-1=$ Past time

$\mathrm{CP}=$ changing Persistence. When CP is ' 0 ' means no change, When CP is $<0$ means decrease, when $\mathrm{CP}$ is $>0$ means increase.

Fig. $2 a$

Fig. $2 b$
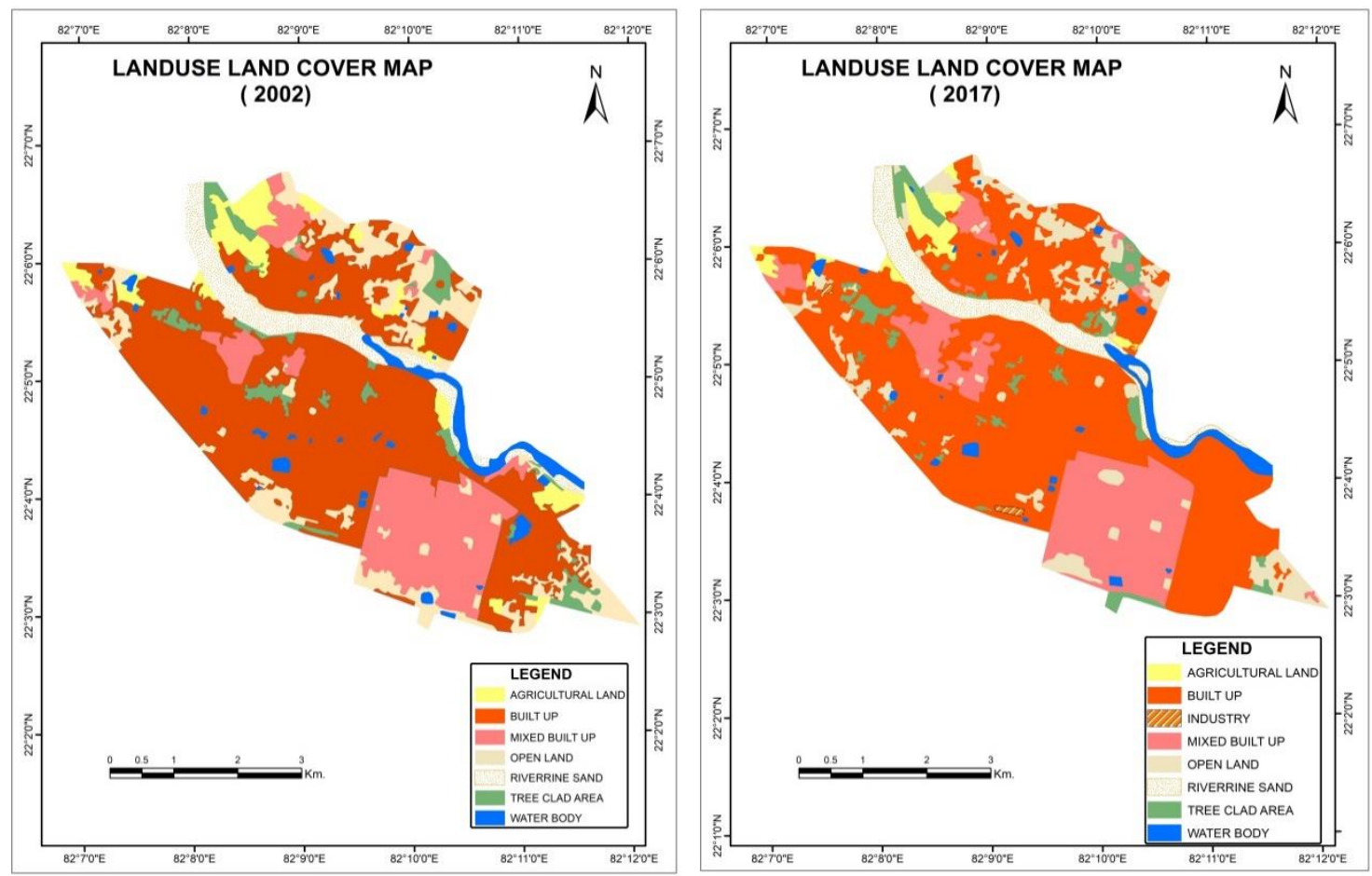

The total area of the rectangular area of interest (AOI) is 22748.4 square kilometers. The details of the land cover of the area under study are given in the following Table 6 below. The table 6 explained the amount of land gained, lost and per year change which was occurred due to transition of one type land cover into another during this period. The buildup land was gained high amount of land (172.4 hector.) as compared to other urban land due to rapid transition of the agricultural land, open land, Tree clad area, and waterbodies into this categories. In the same way mixed built up land was also gained high amount of land (56.6 hector) due to rapid transition of agriculture land, vegetation, waterbodies and industries(very negligible) into this categories. In other hand out of total develop land, agriculture land was rapidly lost (84.89 hector) due to the transition into other urban land as compared to others. Similarly, out of total urban land water bodies (23.83 hector), Tree clad area (1.61 hector) and open land (121.71) were also due to transition into urban land during this period. Therefore, present gross change has 474 hector (gain + losses), out of the total develop land. Thus, out of total developed urban land, built up area was very rapid dynamic rate of positive change $(+172.4)$ and similarly, open land area was very rapidly rate of negative change $(-121.71)$ due to rapid loos rates and slow gain rate as compared to other urban land. Using hand held GPS field survey nearly 100 points were identified. Field knowledge and Google Earth were served as basis for estimation of classification accuracy. 
Table 06: Change of Land use and Land Covers in Bilaspur City, 2002-2017

\begin{tabular}{|c|c|c|c|c|c|c|c|c|c|c|c|}
\hline \multirow[t]{2}{*}{$\#$} & \multirow{2}{*}{$\begin{array}{l}\text { Land use } \\
\text { Categories }\end{array}$} & \multicolumn{2}{|c|}{ In year 2017} & \multicolumn{2}{|c|}{ In year 2002} & \multicolumn{4}{|c|}{ Gross change } & \multicolumn{2}{|c|}{ Per year Change } \\
\hline & & Area & Percent & Area & Percent & Area & Percent & Area & Percent & Area & Percent \\
\hline 1 & Agriculture & 78.07 & 2.56 & 172.96 & 5.67 & --- & ---- & -94.89 & -3.11 & $-\overline{3}$ & -0.21 \\
\hline 2 & Built up & 1716.6 & 56.29 & 1544.2 & 50.64 & 172.4 & 5.67 & --- & -- & 11.49 & 0.38 \\
\hline 3 & Industry & 7.10 & 0.23 & ----- & ----- & ---- & --- & --- & ---- & --- & -- \\
\hline 2 & Mixed Built & 532.79 & 17.47 & 476.19 & 15.61 & 56.6 & 1.86 & --- & -- & 3.77 & 0.12 \\
\hline 5 & Open land & 292.44 & 9.59 & 414.15 & 13.58 & --- & --- & $\begin{array}{c}- \\
121.71\end{array}$ & -3.99 & -8.11 & -0.26 \\
\hline 6 & Riverine & 191.80 & 6.29 & 185.74 & 6.09 & 6.06 & 0.2 & -- & -- & 0.40 & 0.01 \\
\hline 7 & Tree clad Area & 137.82 & 4.52 & 139.43 & 4.57 & --- & ---- & -1.61 & -0.05 & -0.11 & -0.003 \\
\hline \multirow[t]{2}{*}{8} & Water bodies & 93.15 & 3.05 & 116.98 & 3.84 & ---- & --- & -23.83 & -0.79 & -1.59 & -0.05 \\
\hline & Total & 3049.7 & 100 & 3049.65 & 100 & 235.06 & 7.73 & -242.04 & -794 & & \\
\hline
\end{tabular}

Sources: Calculated by author using satellite imageries and referenced dataset, 2002-2017

\section{NDVI Image}

NDVI is one of the most widely used index of which applicability in satellite analysis and in monitoring of vegetation cover was sufficiently verified in the last two decades. The NDVI value of the pixels varies between -1 and +1 . Higher values of NDVI indicate the richer and healthier vegetation. Vegetation affects the latent thermos flux of the surface intent to the atmosphere through the evapotranspiration. Lower LST (except water bodies) is usually measured in areas with higher NDVI values. The Normalized Difference Vegetation Index (NDVI) image developed is shown in the Fig.3a \& $3 b$ below.

Figure: 3a and 3b NDVI image of the Study Area for the year $2002 \& 2017$

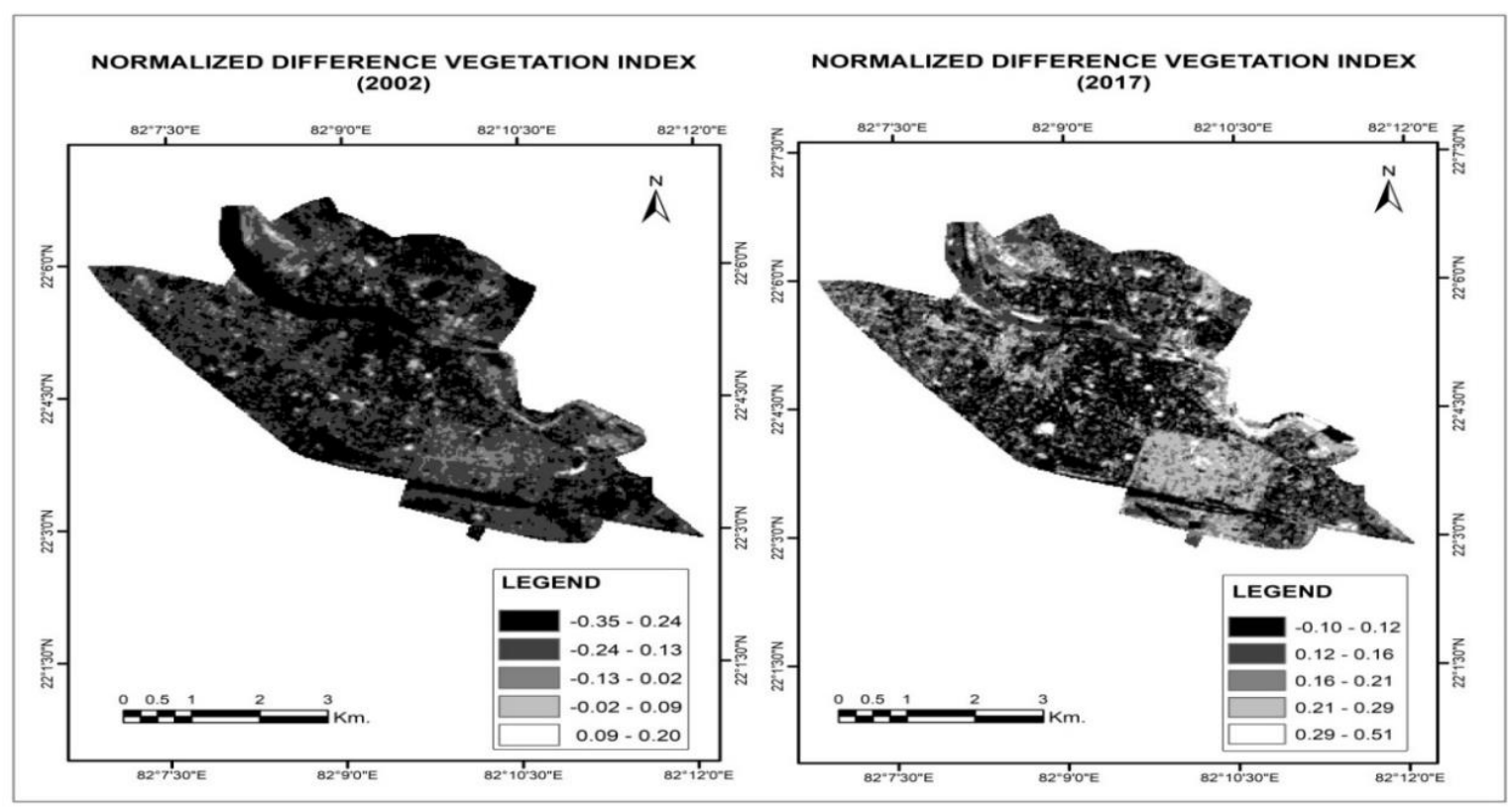

\section{LST Image}

From brightness temperature $\left(T_{B}\right)$ and Emissivity images the final Land Surface Temperature image was obtained by developing a model in ERDAS Imagine 9.1.The Final LST image is shown in the Fig.4a and 4b.

\section{LST and NDVI Relationship}

There is an apparent correlation between LST and NDVI from the visual interpretation of LST and NDVI contrasts. Mean LST and NDVI values associated with different land-use types are significantly different. Multiple comparisons of mean LST and NDVI values associated with pairings of each land-use type are also shown to be significantly different. The result of a regressive analysis shows an inverse correlation relationship between LST and NDVI of 2002 and 2017. 
Figure: 4a and 4b Land Surface Temperature image for the year $2002 \& 2017$

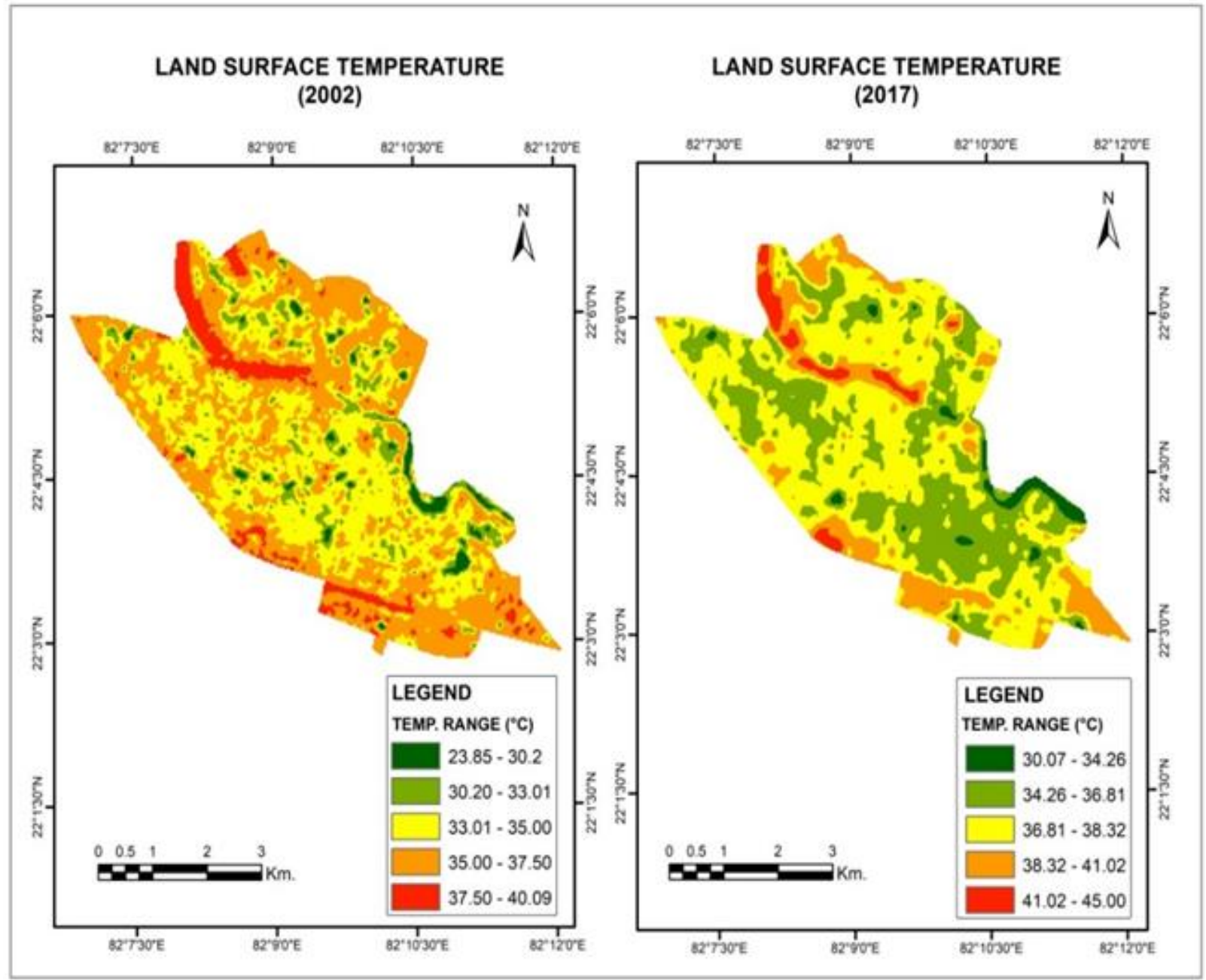

Figure 05: Correlation between LST and NDVI (2002) Figure 06: Correlation between LST and NDVI (2017)
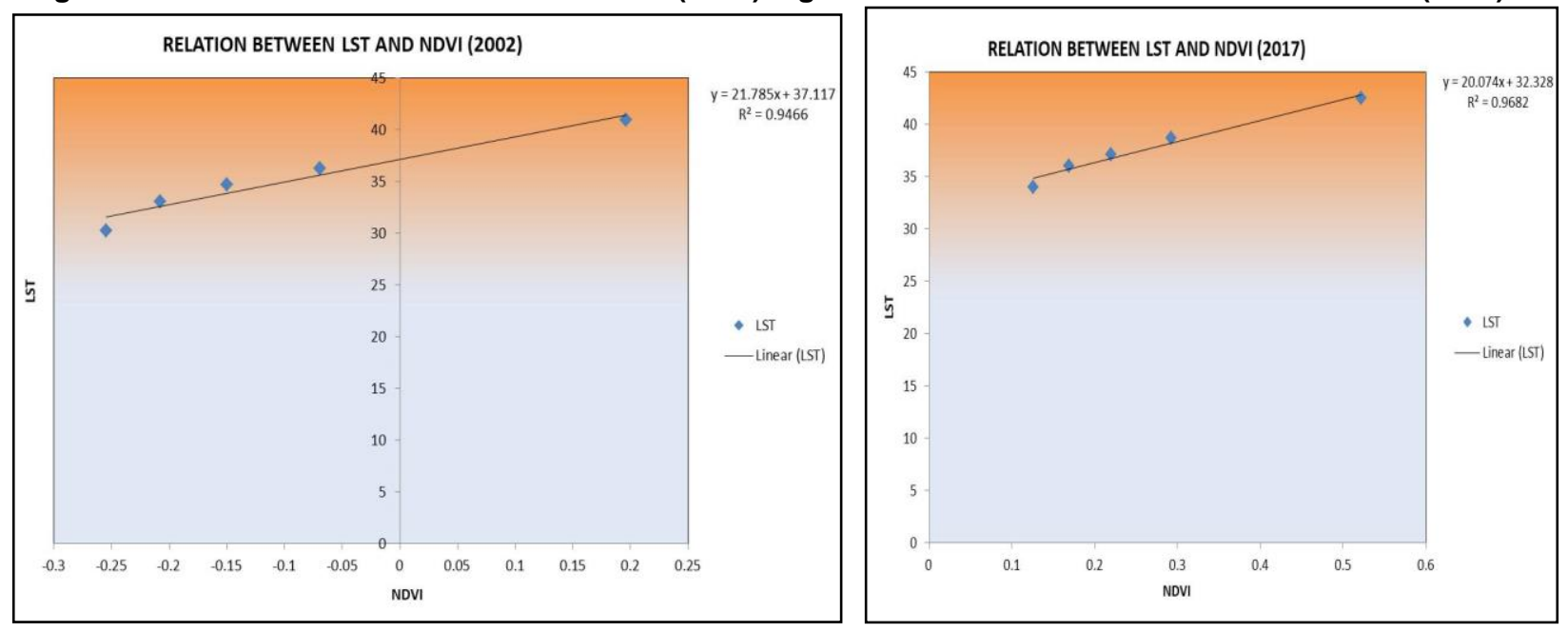

\section{Relation between LULC and LST}

In 2002 Land Surface Temperature (LST) image has highest temperature of about $40^{\circ} \mathrm{C}$ exist in urban built up area of LULC map and other hand impervious area has lowest temperature of about $23^{\circ} \mathrm{C}$ in vegetation area. A surface temperature profile line is drown from South-West end to North-West end of the study area to show the relationship between LULC map and LST map shown in the Fig.7a and 7b. 
Figure 07a and 07b: Land Use / Land Cover Map and Land Surface Temperature line from South West end to the North East end of the study area (2002)

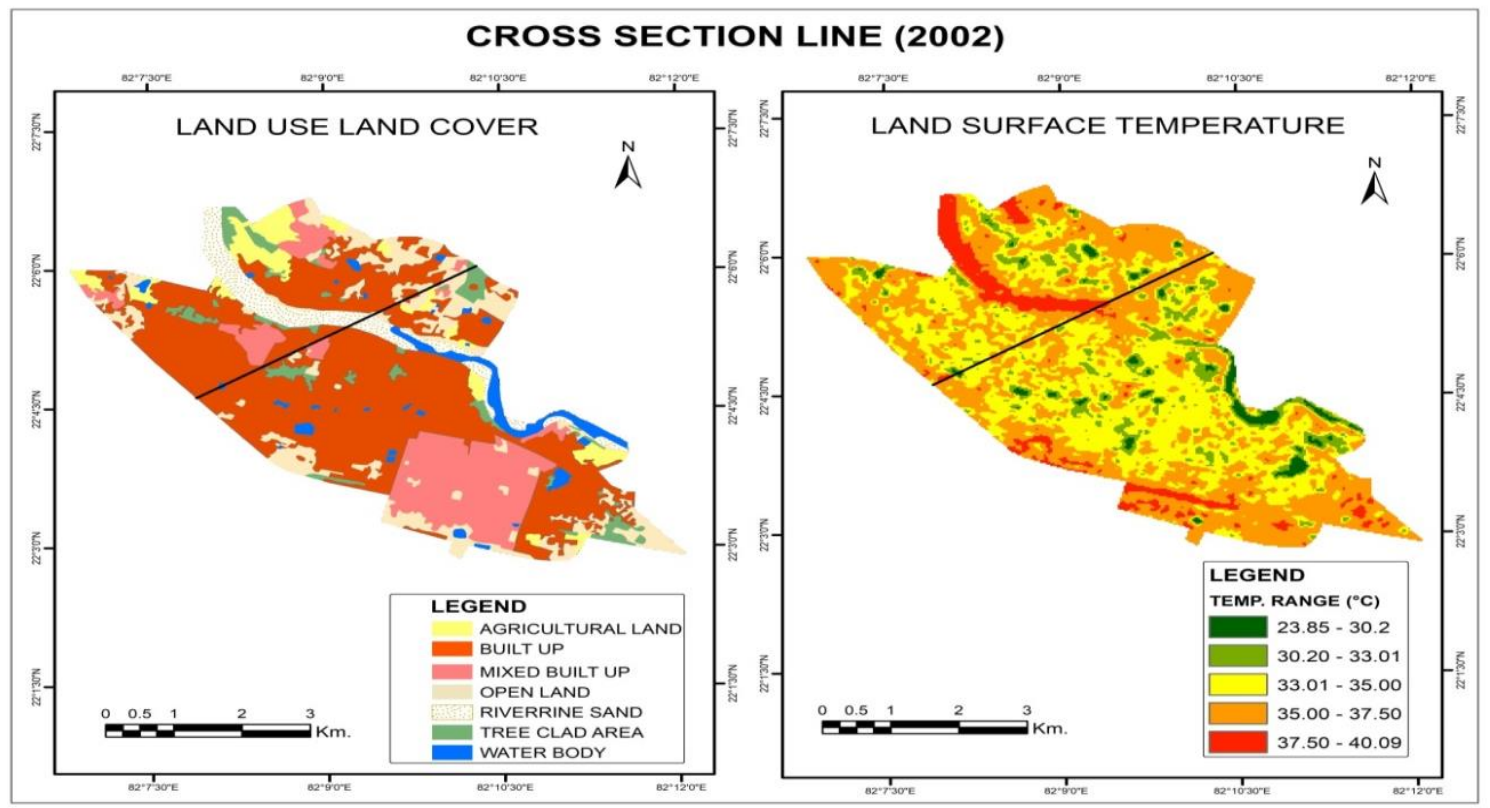

The temperature profiles shown in the Fig.8 below, clearly demonstrates the Urban Heat Island effect. More than 100 points are selected randomly form the LST image and corresponding LULC values are obtained to find the correlation between LULC and LST. In 2017 LST image has observed that highest temperatures of about $45^{\circ} \mathrm{C}$ exist at urban built up and Riverine sandy areas and other impervious areas and lowest temperatures of about $23^{\circ} \mathrm{C}$ are exist at vegetative areas and water body. A Surface temperature profile line is drown from South-West end to North-West end of the study area to show the relationship between LULC map and LST map shown in the Fig.9a and 9b. More than 100 points were selected randomly form the LST values to find the correlation between LULC and LST.

Figure 08: Land Surface Temperature profile from South West end to the North East end

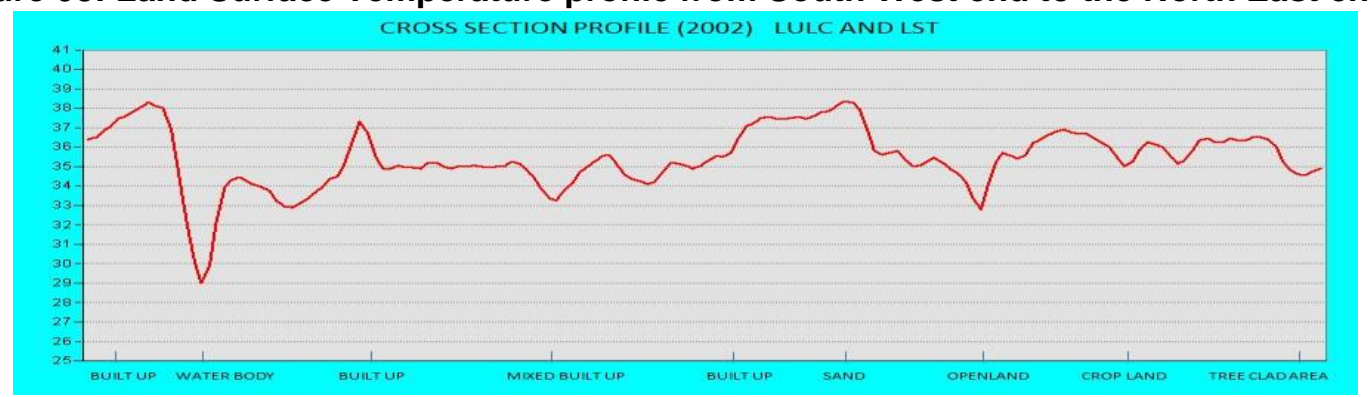

Figure 9a and 9b: Land Surface Temp. Line from South West end to the North East end (2017)

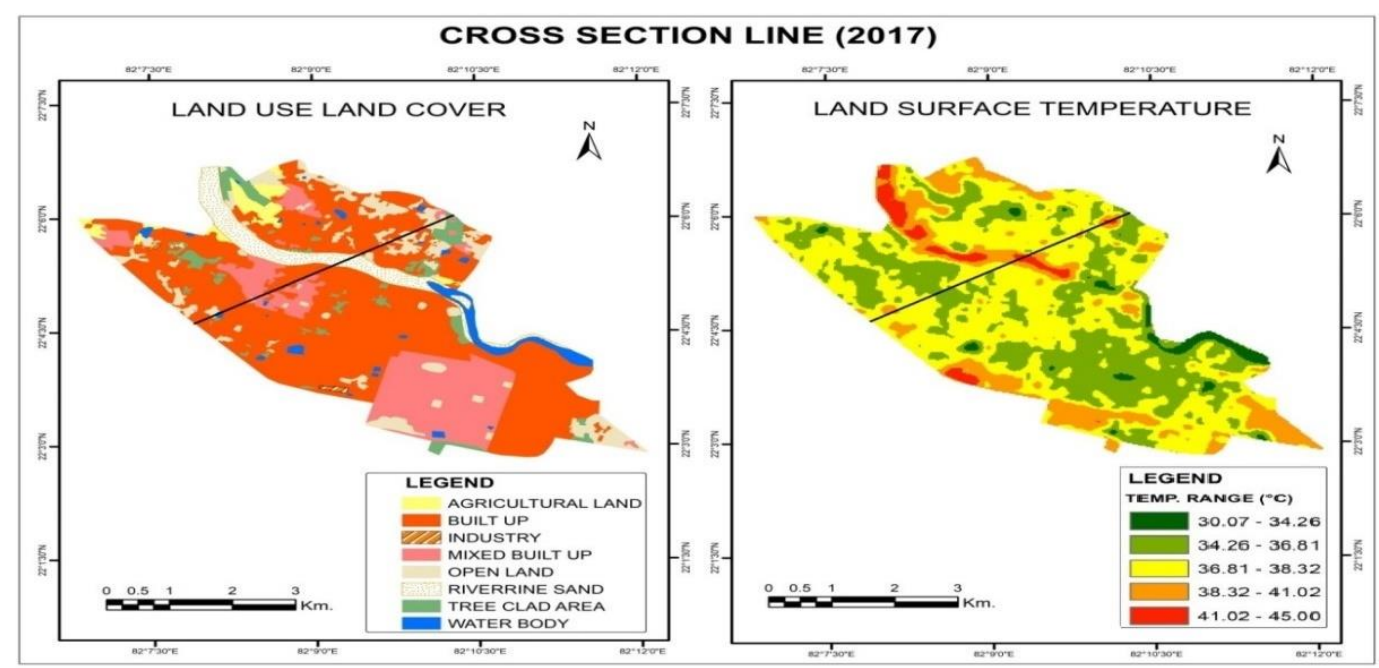


Figure 10: Land Surface Temperature profile from North end to the South end

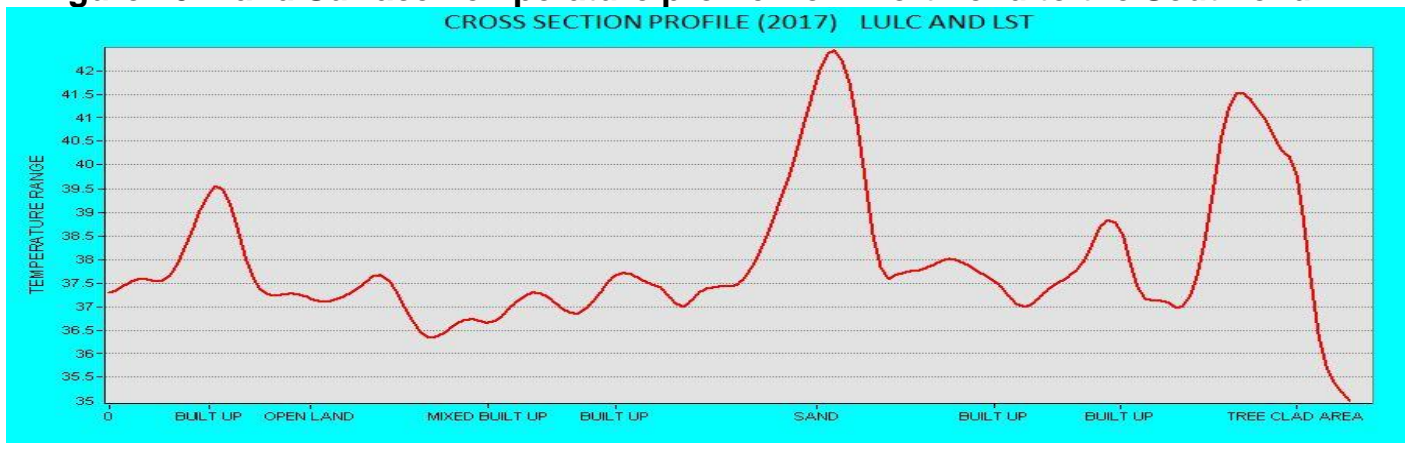

\section{Conclusion and Suggestion}

Bilaspur is the third (after Raipur, Bhilai-Durg) largest city of Chhattisgarh and commercial capital of the state. It is experiencing a rapid urbanization. With urbanization most of the land surface is covered with concrete, asphalt and other such impervious materials. This leads to a variety of urban environmental issues like increase in runoff, increase in land surface temperatures, etc. The cities are experiencing more heat than the surrounding rural areas mainly due lack of vegetative cover. Surface temperature is retrieved to understand the variation of temperature from low density mixed built up area to core built up areas of the city. From the LST images it is clearly understood that surface temperature is more in core built up area compared to fringe areas. Also the correlation study shows that the LST is strongly and negatively correlated with NDVI, which also land use reflect how much brightness temperature. This information assists in monitoring the dynamics of land use resulting out of changing demands of increasing population and associated issues like Urban Heat Island. Average Land surface temperature has increased near about $5^{\circ} \mathrm{C}$ in last 15 years (2002-2017).

Its structure shades anthropogenic surfaces, limiting the accumulation of direct solar radiation and subsequent emission of converted thermal radiation. It increases relative air humidity and reduces air temperature. Besides microclimatic function, vegetation also has health, aesthetic, recreational and other functions. In conclusion, vegetation with higher canopy cover improved environmental conditions in terms of relative humidity. Generally, if increasing the urban zone canopy cover by $50 \%$ would reduce the UHI by 2.05 degrees $\mathrm{C}$. So, this issue is nonstop but it would be minimize this problem It is possible through, maximum plantation in urban Environment, Development of ideal towns (where proper flow of winds direction towards North-South and East-West), Protection of Forests and water bodies, Installation of green roofs (Gardens), Painting roofs with cool material and Use of Non-conventional energy.

\section{References}

1. Li, J. and Zhao, H. M. (2003) "Detecting Urban Land Use and Land Cover Changes in Mississauga using Landsat TM images." Vol 2, No.1, PP.38-47.

2. Mallik, J., Kant, Y. and Bharath, B. D. (2008) "Estimation of land surface temperature over Delhi using landsat-7 ETM+, Journal of Indian Geophysics Union, Vol.12, No.3, P131-140.

3. Oke, T. R. (1973) "City size and the urban heat island." Atmospheric Environment, Vol.7 PP.769-779.

4. Seto, K. C., Woodcock, C. E., Song, C., Huang, X., Lu, J. and Kaufmann, R. K. (2002) Monitoring land-use change in the Pearl River Delta using Landsat TM, Int. J. Remote Sensing, Vol. 23, No. 10, 1985-2004.

5. Torok, S., Morris, C., Skinner, C., Plummer, N. (2001) Urban heat island feature of southeast Australian town. Australian Meteorological Magazine, Vol.50, N0.1, PP.1-13

6. Weng, Q., Lu, D. and Schubring, J., (2004) Estimation of land surface temperaturevegetation abundance relationship for heat island studies, Remote Sensing of Environment, Vol.89 No.4, and PP.467-483. 